\title{
Profession-Based Volunteering as Part of the University Curriculum of Law Students
}

\author{
Andrey Vinogradov ${ }^{1},{ }^{*}$ Maya Pankratova ${ }^{1}$, Elena Kvasyuk ${ }^{1}$, Anna Savchuk ${ }^{1}$ \\ ${ }^{1}$ Murmansk Arctic State University, Russia \\ "Email: andvinogradov00@mail.ru
}

\begin{abstract}
This article is motivated by the topicality of the development of professional competencies of bachelor students. Most of the literature concerning volunteering does not focus on the possibility to incorporate volunteering into the university curriculum. In contrast, this article's main goal was to study university students' attitude to "equating" profession-based volunteering for the internship. Following the goal, the authors had the following objectives: having studied the regulatory framework of volunteering, find if it was possible to combine volunteering with an internship as part of the education process and identify the potential of student volunteering. Authors described the regulatory documents governing volunteer activities, analysed the measures to support volunteering in Murmansk region, and identified the specifics of volunteer activity in an educational organisation (MASU) that law students can do in the framework of university departments or student unions. Based on the analysis of the survey results of 102 bachelor students of Murmansk Arctic State University (Murmansk, Russia), the authors concluded that profession-based volunteering is appealing to university students and helps them acquire professional competencies, which made it possible to count volunteering as internship training. Since internship can occur in an educational organisation or an organisation suitable to the competencies the student must develop, an internship in a volunteer organisation is technically possible since such an organisation is also subject to state certification. To assess student internship prospects in volunteer organisations, this option must be legally formalised for volunteering students. We suggest that including that amendment into legislation will help educational strengthen relations between non-governmental organisations and universities.
\end{abstract}

Keywords: Profession-based volunteering, Student volunteering, Student internship, Professional competencies, Employment.

\section{INTRODUCTION}

Currently changing processes in all spheres of society, the increased state attention to social issues, and the transition from a knowledge-based education model to a competency model point to the need for constant search, improvement, development and implementation of innovative forms of different fields specialists training. Today, there is a need to train highly qualified and competent specialists who possess theoretical knowledge and have professional competencies. Existing training programs for bachelor students include a theoretical course and an internship, and solve specific goals and objectives, gradually forming the necessary general cultural and professional competencies of students, contributing to their professional development. Unfortunately, theoretical training combined with a short internship period does not give graduates the effective results expected by modern society. The theoretical material content does not always coincide with real problems that the student encounters when entering the internship. One of the innovative areas of student learning in the competency-based approach framework should be engaging students in profession-based volunteering [1, pp.5-8].

Profession-based volunteering is considered as an innovative type of activity aimed at the practical training of students, presented in the form of an independent practical tasks system and designed to qualitatively 
complement the existing level of students' training, to increase their professional activity through the provision of free aid to institutions, charitable and public organisations in the implementation of activities aimed at solving urgent problems requiring the participation of volunteers [2, pp.90-93].

Volunteering, in general, has recently become extremely popular with students in Russia. Workforce Survey Bulletin 2016-2019 shows that the number of volunteers in Russia grows every year. In particular, the number rose by 214 thousand people over the described period [3, p.13]. Many researchers connect the rise in volunteering with global importance events, such as the Sochi Olympic Games in 2014, the World Cup in 2018, and the Kazan Universiade in 2013 [3, p.26].

The number of volunteers is also rising because of one of the priorities of government policies. In particular, the President of Russia issued a decree "On holding a Year of the Volunteer in the Russian Federation" declaring 2018 a year of the volunteer. President's Decree No 572 of 27/11/2017 "On Volunteer Day" (5th December). The date is the same as International Volunteer Day established by the UN General Assembly in 1985.

Despite the active encouragement of every person in the country to participate in the volunteer movement, we need to note that young people are the most prominent in the Russian volunteer movement. According to the Federal State Statistics Service, most people involved in volunteer activities are young people aged 15-30.

Murmansk region actively participates in developing youth's volunteering.

11 volunteer centres operate in the region, providing a facility for young people to develop their potential in various activities in the continually changing present-day "risk society" and supporting youth initiatives and projects in the region. Also, an information and consulting environment is being created for volunteers.

Students are the most active group of young people. It is no surprise that they represent most volunteers. However, their main activity is studying. Therefore, the authors try to find a way to organise the learning process so that profession-based volunteering can help the curriculum and motivate students. Thus, in Murmansk Arctic State University encourages to arrange professionbased volunteering based on internship.

\section{REVIEW OF LITERATURE}

The most apparent aspect of student volunteering observed by many authors is that it makes student social work and student communities more efficient. Volunteering is a powerful tool and resources for solving severe social issues and improving the student communities' efficiency that constitutes economic, political and social potential for a country [4, p.184].

It is particularly relevant to our study that several authors view students' volunteer movement both in the context of values and as a possible stage of students' professional development [5, p.31]. We believe that there is a social need for developing that aspect of volunteering. For instance, all countries of the EU are considering volunteer involvement [6, p.8]. It is an ambitious goal requiring many resources and time, and the authors refer to examples of volunteer activities in universities to achieve it.

We hope that universities' activities will have a positive social impact, but what we are more interested in is the impact on students' professional development participating in volunteering programmes. The authors who studied student volunteering in five EU countries concluded that "the growth of service-learning programs (particularly those that are mandatory or compulsory) demonstrates a potential link between undertaking community service learning and achieving educational outcomes" [7 p.78]. We would like to make this link relevant and positive for the learning progress of students.

At the same time, some authors note specific issues volunteering students face: "However, students face several barriers to volunteering, such as the rising costs of education and the need to undertake more paid work, thus reducing the time available to volunteer" [8, p.12]. This fact sets the goal of organising volunteer activities so that they could be combined with successful learning. We agree with the researchers that "volunteer experiences provide significant learning opportunities for higher-education students" [9, p.34] and want to find suitable forms for them.

However, the subject's issue in question is that volunteering is based on voluntary participation: "it is an activity that occurs within organisations without remuneration" [10, p.59], whereas participation in various learning activities is a mandatory requirement of a curriculum.

Scholars have recognised that traditional attitudes to volunteering are limited and limiting in the face of volunteer work reality $[11, \mathrm{p}$.47]. Nowadays, professional skills-based volunteers are often more credentialed and trained in their particular skill set than anyone else in any organisation.

\section{METHODOLOGY}

One of the research objectives was to survey to find out students' attitude to profession-based volunteer work and the opportunity to develop necessary skills and competencies through profession-based volunteering in 
organisations provided by Murmansk Arctic State University.

The study adopted such research methods as the electronic questionnaires since the method is the most suitable for collecting input data and consistent with the study's goals and objectives. The survey was done by the social-studies laboratory of MASU equipped with the latest SPSS IBM Statistics version. This program covers the whole process of statistical analysis - planning, data collection, analysis and reporting. IBM SPSS Statistics platform allows you to analyse big data to obtain predictive information and formulate an effective strategy. It also creates timely reports and visualisations.

The experiment was conducted within three academic years. The authors were interested to know the possible changes in the students' attitudes to profession-based volunteering.

The sampling includes students from Murmansk Arctic State University (aged 17-26).

102 respondents took part in the electronic survey. They were full-time $3 \mathrm{rd}$ and $4^{\text {th }}$ academic year bachelor students of the Law department.

Most of the students were 17-21 years old: 51\%. The second-largest group was 22-26 years old: 49\%. The share of women was $60.8 \%$, men $39.2 \%$.

The questionnaire combined open-ended questions and multiple-choice questions with predefined answers offering respondents the possibility to choose and rank among several options or grade on a "very low" to "very large" scale. For these questions, and optional space was provided to elaborate on the answer. This open part is considered of great importance for a survey of this kind. It contributes to improving the interpretation of its overall results and provides additional valuable material.

The survey had two stages. At the first stage, that took place at the beginning of the academic year; we studied Law department students' attitudes towards professionbased volunteering. The questionnaire at this stage consisted of 3 questions:

1. What is your attitude toward volunteering?

2. Have you got any experience in profession-based volunteering?

\section{What organisations have you volunteered in?}

The second stage of the survey was divided into two parts. The first part took place before the Law students had had their internship or academic training in their professional sphere. The second part took place right after the internship. Thus, we identified the number of students who wanted to have their internship or academic training in university departments involved in professionbased volunteering. Apart from that, we studied what motivated them to make that choice. The respondents were asked the following questions:

1. What internship facility would you like to choose:

A. MASU profession-based organisations

B. Other volunteer organisations

2. Why have you made this choice?

A. To gain professional competencies

B. To get further employment opportunities

C. To combine studies with volunteering (to get credits for internship)

\section{FINDINGS AND DISCUSSIONS}

The first stage of the study confirmed the general European trend of increasing interest in volunteering and rising numbers of volunteers. According to an annual survey of first-year students in Murmansk Arctic State University done by the social studies laboratory, the number of people willing to participate in the universityled volunteering is rising each year (figure 1).

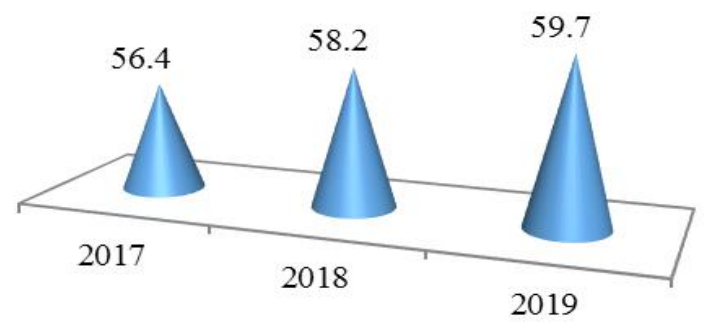

Figure 1 Number of MASU students interested in volunteering ( $\%$ of the total surveyed).

As far as students' attitudes towards profession-based volunteering are concerned, we can generally conclude the following:

- most of them approved of people who work without seeking financial gain (figure 2);

- 3/4 of the students surveyed had already participated in volunteer activities, with just a quarter without that experience (figure 3 ).

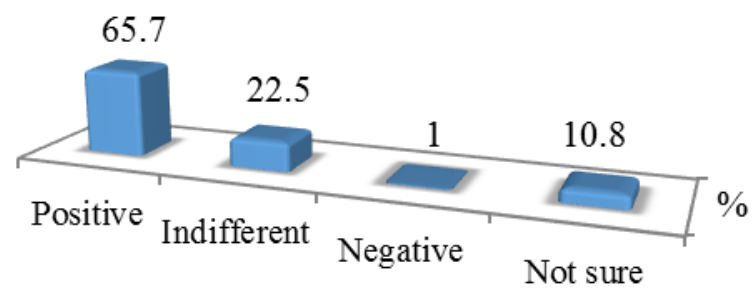

Figure 2 Attitudes of MASU students towards volunteers, $\%$ of respondents. 


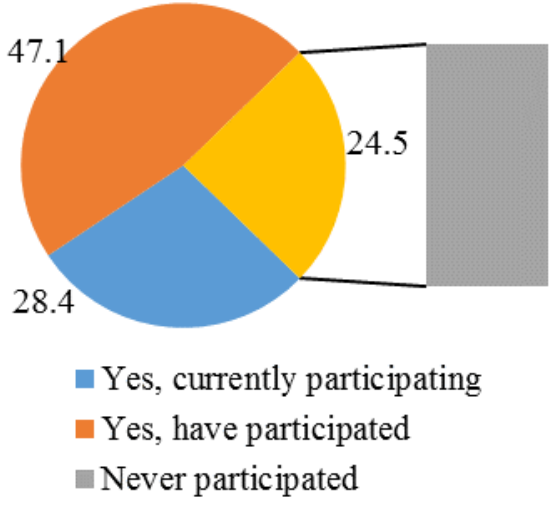

Figure 3 Volunteering experience, \% of respondents.

The identified factors create a favourable environment for engaging students in volunteering, organised by various institutions. Apart from that, the study found a positive attitude towards participating in volunteer projects of the university. Over half of the respondents say that they specifically prefer projects like those (figure 4).

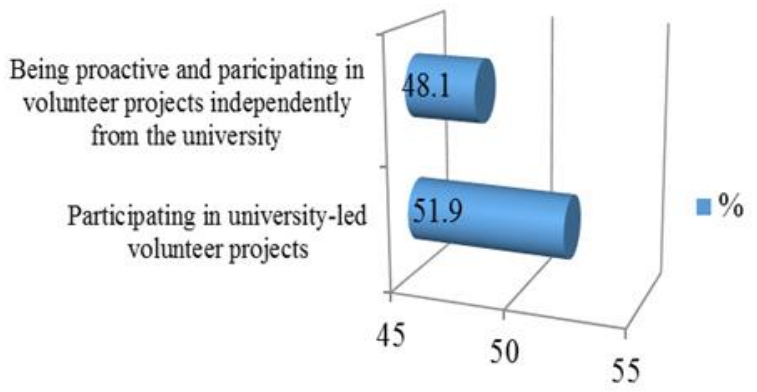

Figure 4 The connection between involvement in volunteering and university studies, $\%$ of respondents.

The first stage of the study showed that almost $66 \%$ of the respondents approved of volunteering, $75.5 \%$ of the students had experience in such activities, and over half of them preferred to participate in volunteer projects organised by the university. We believe that it is an excellent result that allows a further study since over half of the students would like the university to be involved.

The second stage of the study was to assess the model of profession-based volunteering that could provide a combination of learning with university internship. We believe that a way to reach that objective is to count volunteering as a student internship.

A legal framework for combining volunteering with academic and internship training is set in a provision of Order of the Russian Ministry of Education and Science No 1383 of 27th November 2015. It states that highereducation students' practical training may occur both in the educational organisation itself and in organisations consistent with the students' competencies as defined in the relevant state standard of higher education. Volunteer activities may be organised by both individuals and NGOs subject to state registration.
It allows students of Law department to choose, as their internship location, a volunteer NGO or a volunteering department in the educational organisation. For instance, in MASU, an internship may be based at:

1. The Legal Clinic - where students advise people on legal issues in various areas of law. Participating students explain and reference legal issues and help people draw up complaints, claims, contracts, and other legal documents.

2. The School of Legal Information for Young People, a student volunteer community, carries out several volunteer activities, such as improving young people's legal literacy, involving them in education, science, and culture, and helping their personal development.

The students were given a choice of internship facilities, including, without limitation, one of those facilities.

Firstly, the authors surveyed the students before their internship. In contrast, at the second stage, the authors were interested in finding how many students had chosen volunteer organisations for an internship and the motivation behind that choice.

As a result, about a third of the students chose a volunteer organisation for internship: $31.4 \%$ (figure 5).

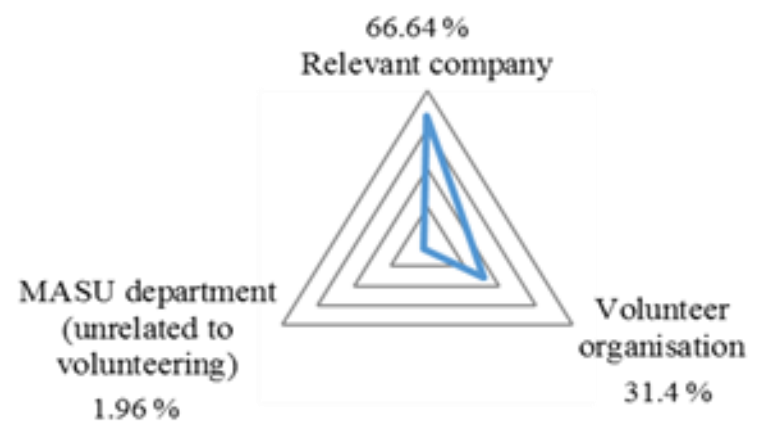

Figure 5 Students' choice of an internship facility.

Over half of the students who had their internship in a volunteer organisation stated that it was a MASU department related to volunteering activities: $56 \%$ of the students (figure 6).

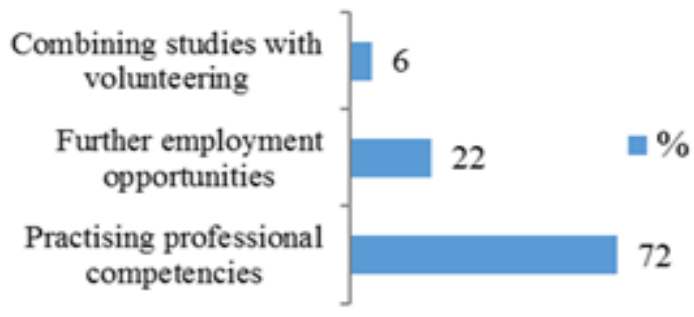




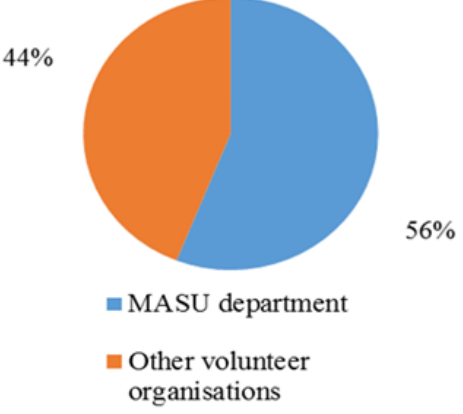

Figure 6 Students' choice of volunteer organisations as an internship facility.

As we can see, the law students chose the MASU department as their internship facilities. The choice was perfectly reasonable, since participating in the Legal Clinic and School of Legal Information work means having specialised legal knowledge.

The authors' next objective was to identify the motivation for choosing the university profession-based volunteering organisations as an internship facility. Of all the students who chose a university-based volunteering organisation for their internship training, $72 \%$ noted that they had done it to get experience in their professional field and practise their professional competencies. 22\% stated that they had already worked with the organisations in their free time and considered further employment in those organisations. The remaining $6 \%$ noted they wanted to combine their studies with volunteering to save time (figure 7).

Figure 7 The motivational aspect of students' internship in volunteer organisations.

It should be noted that the result of studying the motivation of choosing the university organisations for internship surprised the researchers. We had expected that most students would choose the university-based volunteer organisations out of convenience because they made it possible to combine studies with volunteering. The result was the opposite. Most law students chose the university's volunteering departments for internship training because those activities helped them develop their professional competencies best rather than combine volunteering with their studies. The competencies they acquired in the volunteering activities were formally included in the internship report and the volunteer's electronic account, making it possible for the university's internship manager to double-check them.

The result also made us pay attention to the fact that the most responsible and highly motivated students were the most likely volunteers. It prompted us to carry out another study we had not planned to compare the motivation behind the university-based volunteer organisations' choice for internship and the students' academic grades. The results are shown in table 1.

As we can see, our assumption generally proved to be true. Despite the higher share of excellent marks in the students from motivation group 2, the total share of $5 \mathrm{~s}$ and $4 \mathrm{~s}$ was lower than in the students from motivation group 1 . The academic grades of group 1 and 2 were also higher than the students who had chosen the university volunteer organisations for an internship out of convenience.

Academic and internship training of students in university volunteer organisations can only be sufficiently practical. The professional competencies are consistent with the professional competencies the volunteer organisation can develop. For that purpose, we compared the functions, tasks, activities, and duties of the volunteer organisations members. The students had their internship with professional competencies to be acquired by the students by the internship programmes. We analysed the official regulatory documents of the volunteer organisations where the surveyed students had their internship. The analysis showed that their activities are mostly consistent with the competencies to be developed during the internship. The results are shown in table 2 .

This comparative analysis of the correlation of organisation profiles and internship competencies proves that profession-based volunteering in specialised volunteer organisations for Law students can help develop professional skills and acquire necessary professional competences.

\section{CONCLUSION}

For students who are actively involved in volunteering, such an internship option may be a measure to support the volunteer movement. Including those

Table 1. Correlation between internship motivation and academic grades of students

\begin{tabular}{|l|l|c|c|c|}
\hline \multirow{2}{*}{} & Type of motivation to choose an internship & \multicolumn{3}{|c|}{ Grades of the previous year (\%)* } \\
\cline { 3 - 5 } & & 5 & 4 & 3 \\
\hline 1 & Pacility & 27.3 & 53.7 & 19 \\
\hline 2 & Further employment opportunities & 28.8 & 47.3 & 23.9 \\
\hline 3 & Combining studies with volunteering & 21.3 & 48.6 & 30.1 \\
\hline
\end{tabular}

*Note: 5 - excellent (A); 4 - good (B); 3 - satisfactory (C) 
Table 2. Correlation of organisation profiles and internship competencies

\begin{tabular}{|c|c|c|}
\hline № & Activity of organisation & Professional competencies to be developed \\
\hline 1 & \multicolumn{2}{|c|}{ Legal clinic (legal advice by students) } \\
\hline & $\begin{array}{l}\text { Free legal assistance by law students } \\
\text { as part of a non-government system } \\
\text { of free legal assistance using oral and } \\
\text { written advice, drawing up complaints, } \\
\text { claims, contracts, and other legal } \\
\text { documents for the constitutional right } \\
\text { for free legal assistance, controlled by } \\
\text { qualified lawyers responsible for } \\
\text { training }\end{array}$ & $\begin{array}{l}\text { - can carry out professional activities based on a high } \\
\text { standard of legal consciousness, judgement, and culture; } \\
\text { - can ensure compliance with the Russian Federation law by } \\
\text { legal persons; } \\
\text { - can make decisions and legal actions in strict compliance } \\
\text { with the Russian Federation law; } \\
\text { - can enforce legal acts and regulations of substantive and } \\
\text { procedural law in professional activities; } \\
\text { - can assess facts and circumstances in a legally accurate } \\
\text { manner; } \\
\text { - can draw up legal documents. }\end{array}$ \\
\hline 2 & \multicolumn{2}{|c|}{ School of Legal Information for Young People, a student volunteer community } \\
\hline & $\begin{array}{l}\text { Developing legal literacy and } \\
\text { encouraging legal knowledge in } \\
\text { school and university students and any } \\
\text { interested persons in the Murmansk } \\
\text { Region to form a proactive attitude } \\
\text { towards improving legal consciousness } \\
\text { and culture and preventing child } \\
\text { neglect and juvenile delinquency }\end{array}$ & $\begin{array}{l}\text { - ready to implement the curriculum following standards of } \\
\text { education; } \\
\text { - can use modern methods and technologies of training and } \\
\text { assessment; } \\
\text { - can perform tasks in encouraging values and moral } \\
\text { development in curricular and extracurricular activities; } \\
\text { - can use a learning environment to achieve personal, meta } \\
\text { disciplinary and subject-related results of education and } \\
\text { ensure the quality of education and training in the subjects } \\
\text { taught; } \\
\text { - can guide learners' socialisation and choice of profession; } \\
\text { - willing to communicate with participants of a learning } \\
\text { process; } \\
\text { - can manage learners' cooperation, encourage their activities, } \\
\text { initiatives and independence, and develop their creativity. }\end{array}$ \\
\hline
\end{tabular}

options for volunteering students into the law may help assess that measure's efficiency for educational organisations and volunteer organisations. Besides, that amendment helps encourage students to realise their potential in profession-based volunteering. It enables educational organisations to expand the available internship facilities and then establish cooperation with socially orientated NGOs.

Profession-based volunteering offers such a wide range of activities that students studying for different subjects can develop their general professional, universal, and cultural competencies by engaging in various volunteering activities. Since volunteering helps develop and improve social and professional competencies, we can raise the question of equating volunteering activities to university internship, including relevant amendments in the law. Moreover, the growing number of students willing to engage in volunteering is even more relevant to introducing those learning practices.

The study of university students' attitude to profession-based volunteering as part of the curriculum can be considered positive.

\section{ETHICAL STATEMENT}

All actions were coordinated with the management of the institutions where the study was conducted. All rights and freedoms of pupils and their parents were respected. The results are implemented in practice. 


\section{REFERENCES}

[1] A. Morris, Professional Development and Volunteerism Can Go Hand in Hand. Journal of Nutrition Education and Behaviour Vol. 51 Iss. 1 (2019) 1 . DOI: https://doi.org/10.1016/j.jneb.2018.11.009

[2] K. McAllum, Meanings of Organizational Volunteering: Diverse Volunteer Pathways. Management Communication Quarterly 28(1) (2014) 84-110. DOI: https://doi.org/10.1177/0893318913517237

[3] Rosstat Examination of Labour Force 2016-2019. Retrieved 30th December 2019, from: https://gks.ru/compendium/document/13265

[4] I.V. Antonovich, Students' volunteering as a tool for solving social policy problems. Sociology in the modern world: science, education, creativity 7 (2015) 183-186.

[5] M.V. Pevnaya, Student volunteering: features of activity and motivation. Higher education in Russia, 6. Retrieved 26th December 2019, from: https://cyberleninka.ru/article/n/studencheskoevolonterstvo-osobennosti-deyatelnosti-i-motivatsii

[6] F. McGuinness, \& M. Ward, Social Mobility Commission, State of the Nation report.p, 2017, Number CDP-2017-0099, 21 March 2017.

[7] K.A. Smith, K. Holmes, D. Haski-Levenhal, R.A. Cnaan, F. Handy, \& J.L. Brudney, Motivations and Benefits of Student Volunteering: Comparing Regular, Occasional, and Non-Volunteers in Five Countries. Canadian Journal of Non-profit and Social Economy Research 1(1) (2010) 65-81.

[8] E. Evans, \& J. Saxton, The 21st century volunteer. London: NpfSynergy.

[9] A. McFadden, \& K. Smeaton, Amplifying Student Learning through Volunteering. Journal of University Teaching \& Learning Practice, 14(3), Art. 6. Retrieved 14th December 2019, from: http://ro.uow.edu.au/jutlp/vol14/iss3/6

[10] L. Hustinx, F. Handy, \& R. Cnaan, 2012, Student volunteering in China and Canada: Comparative perspectives. Canadian Journal of Sociology 37(1) (2005) 55-83.

[11] L.K. Lewis, An Introduction to Volunteering, M.W. Kramer, L.K. Lewis, \& L.M., 2013.

[12] Gossett (Eds.), Volunteering and Communication: Studies from Multiple Contexts, Vol. 1, pp. 1-24, New York: Peter Lang.
[13] Steimel, Sarah, Skills-Based Volunteering as Both Work and Not Work: A Tension-centred Examination of Constructions of "Volunteer" Papers in Communication Studies, 2018, 182. 